\title{
ESTUDO COMPARATIVO DA DEFINIÇÃO DE ANOS-PADRÃO DO REGIME HABITUAL E EXCEPCIONAL DAS PRECIPITAÇÕES A PARTIR DO ANO CIVIL E DO ANO HIDROLÓGICO
}

\author{
Diego Tarley Ferreira Nascimento ${ }^{(a)}$, Ramonielly Malaquias Moreira de Deus ${ }^{(b)}$
}

(a) Professor do curso de Geografia da Universidade Estadual de Goiás - Campus Iporá, diego.tarley@ gmail.com

(b) Acadêmica do curso de Geografia da Universidade Estadual de Goiás - Campus Iporá, nielly-go@ hotmail.com

\section{Eixo: 3 Climatologia em diferentes níveis escalares: mudanças e variabilidades}

\section{Resumo/}

A Climatologia Geográfica prega não serem necessárias extensas séries temporais de dados meteorológicos, podendo ser utilizados anos-padrão, considerados como recortes amostrais do regime habitual e o excepcional do clima. Porém, é preconizada a questão de que o uso do ano civil talvez não seja o mais adequado para a definição dos anos-padrão, em decorrência da não correspondência do ano civil com o ano hidrológico para o caso de algumas regiões do Brasil. Nesse sentido, busca-se no presente trabalho comparar a definição de anos-padrão a partir do ano civil e do ano hidrológico, empregando-se a técnica dos quantis e valendo-se de 13 estações localizadas em Goiás, Distrito Federal e entorno. $\mathrm{O}$ trabalho discute a não adequação do calendário civil para a definiçao dos anospadrão, por não compreender toda a extensão do período chuvoso e não retratar os sistemas atmosféricos responsáveis pela condição habitual ou excepcional das chuvas.

Palavras chave: Anos-padrão; Regime; Precipitação; Chuva; Climatologia.

\section{Introdução}

O desenvolvimento da ciência climatológica teve como primórdio a abordagem de uma Climatologia Separatista (Tradicional), de caráter essencialmente quantitativo e com uso abusivo de medias. Com o decorrer do tempo, ela passa a incorporar a noção da circulação geral da atmosfera, a ponto de se desenvolver uma segunda corrente teórico-metodológica: a Climatologia Sintética (Dinâmica), a qual defende a análise integrada do clima no ritmo de sucessão habitual, com a necessidade de recorrer à dinâmica atmosférica traduzida pela atuação das massas de ar (BARROS; ZAVATTINI, 2009).

Mais recentemente, Sant'Anna Neto (2001, p. 55) considera a abordagem de uma nova corrente dessa ciência, identificada como "Climatologia Geográfica", tendo como o paradigma do clima o "encadeamento, sucessivo e contínuo, dos estados atmosféricos e suas articulações no sentido de retorno aos mesmos estados", tratado por Monteiro (1971, p. 10) como sendo o ritmo climático. 
XVII Simpósio Brasileiro

de Geografia Física Aplicada

I Congresso Nacional

de Geografia Física
OS DESAFIOS DA GEOGRAFIA FÍSICA NA FRONTEIRA DO CONHECIMENTO

Instituto de Geociências - Unicamp

Campinas - SP

28 de Junho à 02 de Julho de 2017

A Climatologia Geográfica prega não serem necessárias extensas (e problemáticas) séries temporais de dados, como o caso dos 30 anos indicados pela Organização Mundial de Meteorologia. Podendo ser empregadas séries temporais menores, desde que maiores que 10 anos e comum a todas as estações. Sendo assim, sugere-se a utilização de anos-padrão ou mesmo episódios-padrão, considerados por Monteiro (1971, p. 10) como recortes amostrais capazes de refletir o habitual e o excepcional no que diz respeito ao quadro climático de determinada localidade.

Diversos foram os estudos que valeram-se do recorte de anos-padrão para estudar o ritmo habitual e excepcional das chuvas, dentre os quais vale destacar o trabalho pioneiro de Monteiro (1973), os que o sucederam, Zavattini (1990), Aouad (1982), Boin (2000), Barros (2003), e tantos outros.

Geralmente são empregados os totais anuais (critério quantitativo) e o regime de precipitação percebido entre os acumulados mensais (critério qualitativo) para identificação e definição dos anos-padrão habituais e excepcionais (ZAVATTINI, 1990; MONTEIRO, 1971, 1973).

Contudo, em recente estudo sobre as chuvas no estado de Goiás e Distrito Federal, Nascimento (2016) levanta a questão de que o uso do ano civil (janeiro a dezembro) talvez não seja o mais adequado para a definição dos anos-padrão. Isso em decorrência da não correspondência do ano civil com o ano hidrológico (começo ao término da estação chuvosa) para o caso de algumas regiões do Brasil, como foi o caso da área estudada pelo autor.

Nesse sentido, o objetivo geral do presente trabalho é apresentar um estudo comparativo da definição de anos-padrão do regime habitual e excepcional das precipitações a partir do ano civil e do ano hidrológico, tendo como estudo de caso o território compreendido pelo estado de Goiás e Distrito Federal.

\section{Procedimentos Metodológicos}

A área em estudo compreende o estado de Goiás e o Distrito Federal,que faz parte da região Centro-Oeste

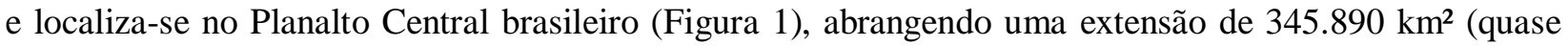
$4 \%$ do território nacional), sendo $340.111 \mathrm{~km}^{2}$ referentes à Goiás e $5.779 \mathrm{~km}^{2}$ ao Distrito Federal.

Strahler (1951) identifica para a área em estudo um clima das baixas latitudes, controlado por massas de ar equatoriais e tropicais, e que apresentam caráter tropical quente e semiúmido. A temperatura média anual é de $22^{\circ} \mathrm{C}$, sendo $24{ }^{\circ} \mathrm{C}$ para o mês mais quente e $18{ }^{\circ} \mathrm{C}$ para o mais frio, ao passo que a média de precipitação anual varia espacialmente entre 1.500 e $1.750 \mathrm{~mm}$, com período de estiagem de até cinco meses, referente aos meses de maio a setembro e o trimestre consecutivo mais chuvoso referente aos meses de dezembro a fevereiro (NIMER, 1979). 


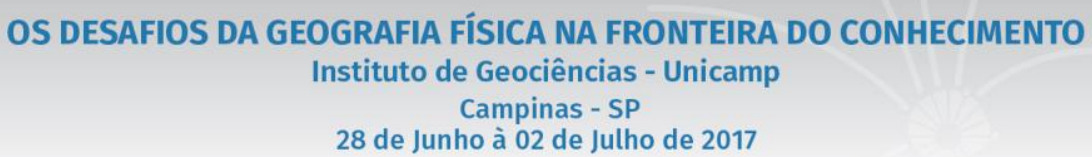

Campos et al. (2002) destacam que, devido à considerável diversidade do relevo, da hidrografia, da vegetação, da latitude, da continentalidade e da dinâmica das massas de ar (os fatores climáticos), o estado de Goiás e o Distrito Federal apresentam uma complexa variabilidade climática, principalmente térmica e pluviométrica. Nimer (1979) complementa que os fatores relevo e latitude traduzem a diversidade térmica da região, isso porque a variação da latitude reflete maiores temperaturas no norte $\left(24{ }^{\circ} \mathrm{C}\right)$ e menores no sul $\left(22{ }^{\circ} \mathrm{C}\right)$, enquanto o relevo faz com que locais com menores altitudes possuam média entre $22{ }^{\circ} \mathrm{C}$, diminuindo para $20^{\circ} \mathrm{C}$ em áreas mais elevadas, como ocorre nas imediações do Distrito Federal.

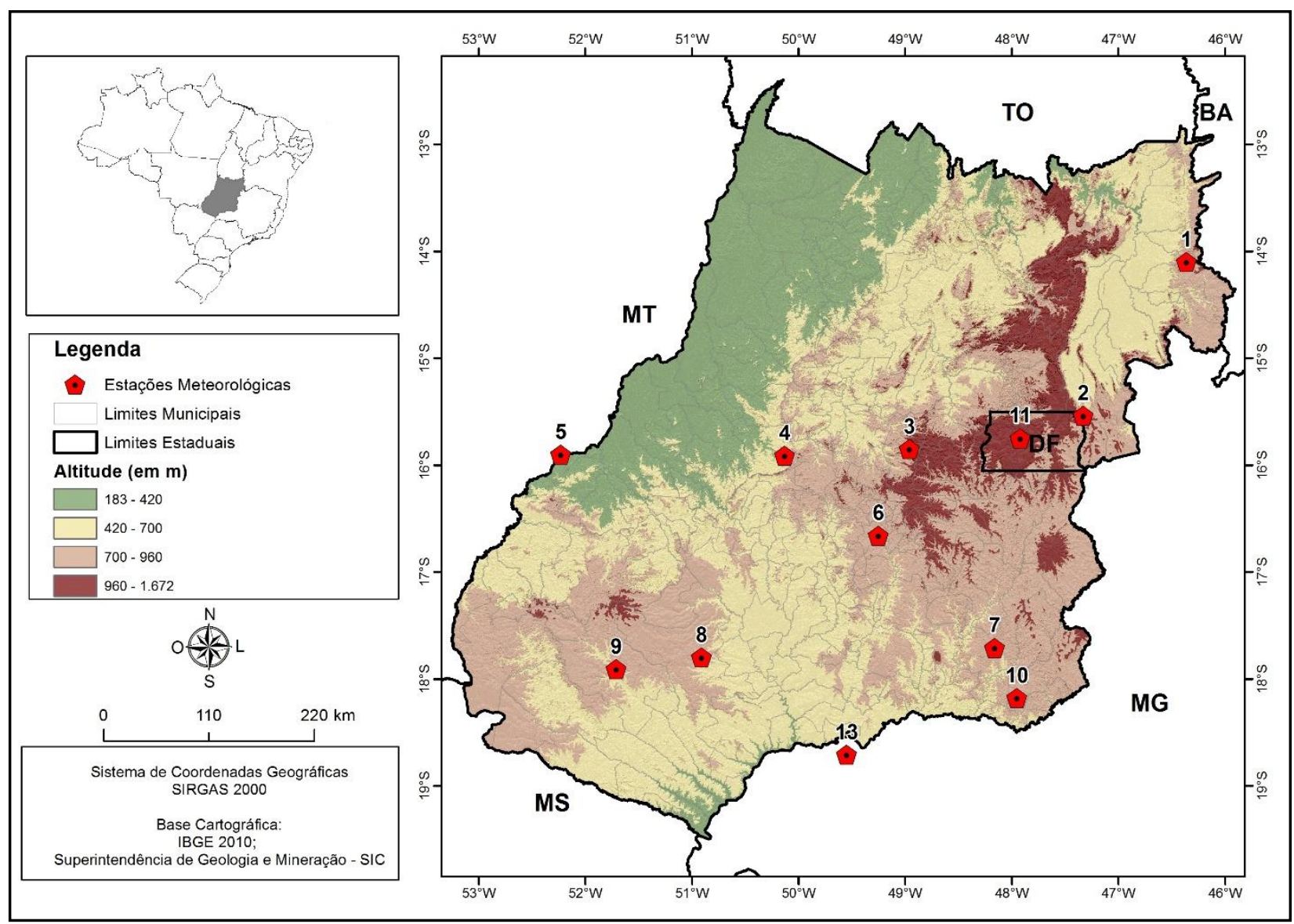

Figura 1 - Localização da área em estudo e estações meteorológicas selecionadas. Elaboração: próprios autores.

Os procedimentos metodológicos consistiram, inicialmente, na identificação e compilação dos dados mensais de precipitação de13 estações meteorológicas convencionais do Instituto Nacional de Meteorologia (INMET) situadas em Goiás, no Distrito Federal e também no entorno da área em estudo, listadas pelo Quadro 1e representadas graficamente pela Figura 1. 
Considerando as falhas de dados dentre as estações meteorológicas selecionadas, foi determinada uma série temporal comum a todas, sendo o período de 1996 a 2016 - compreendendo 20 anos. Após a definição da série temporal, foram calculados os totais anuais considerando o ano civil (janeiro a dezembro) e o ano hidrológico (julho de ano a junho do ano seguinte).

Quadro 1 - Relação das estações meteorológicas convencionais do INMET utilizadas

\begin{tabular}{|c|c|c|c|c|c|c|c|}
\hline Número & Lat & Long & Municipio & UF & Código & Altitude & Implantação \\
\hline 1 & $-14,1$ & $-46,36$ & Posse & GO & 83332 & 825 & 1975 \\
\hline 2 & $-15,54$ & $-47,33$ & Formosa & GO & 83379 & 935 & 1925 \\
\hline 3 & $-15,85$ & $-48,96$ & Pirenópolis & GO & 83376 & 740 & 1977 \\
\hline 4 & $-15,91$ & $-50,13$ & Goiás & GO & 83374 & 512 & 1946 \\
\hline 5 & $-15,9$ & $-52,23$ & Aragarças & GO & 83368 & 345 & 1970 \\
\hline 6 & $-16,66$ & $-49,25$ & Goiânia & GO & 83423 & 741 & 1937 \\
\hline 7 & $-17,71$ & $-48,16$ & Ipameri & GO & 83522 & 772 & 1977 \\
\hline 8 & $-17,8$ & $-50,91$ & Rio Verde & GO & 83470 & 774 & 1971 \\
\hline 9 & $-17,91$ & $-51,71$ & Jataí & GO & 83464 & 662 & 1978 \\
\hline 10 & $-18,18$ & $-47,95$ & Catalão & GO & 83526 & 840 & 1913 \\
\hline 11 & $-15,75$ & $-47,92$ & Brasília & DF & 83377 & 1159 & 1961 \\
\hline 12 & $-12,01$ & $-48,35$ & Peixe & TO & 83228 & 242 & 1975 \\
\hline 13 & $-18,71$ & $-49,55$ & Capinópolis & MG & 83514 & 620 & 1969 \\
\hline
\end{tabular}

Elaboração: próprio autor, com base no INMET.

Para definição dos anos-padrão habitual e excepcional foi empregado o método dos quantis, utilizado, pela primeira vez, por Pinkayan (1966) e destacado por Xavier et al. (2002) como capaz de dar melhor significado às alturas pluviométricas. O quantil se baseia numa medida separatriz, em que os dados de um universo amostral são ordenados e separados em subconjuntos de dimensões identificas com intervalos definidos de acordo com a função de distribuição (tercis = três subconjuntos; quartis = quatro subconjuntos; quintis $=$ cinco subconjuntos; decis $=$ dez subconjuntos e; percentis $=$ cem subconjuntos $)$.

Com o intuito de melhor identificar o regime habitual e excepcional das chuvas na região em estudo, foram delimitadas cinco classes de regime de precipitação e, diferentemente dos intervalos utilizados por Pinkayan (1966) e Xavier et al. (2002), foram empregados os percentis de P0,5, P0,25, P0,75 e P0,95, para representar os anos Muito Seco (MS), Seco (S), Habitual (H), Chuvoso (C) e Muito Chuvoso (MC), respectivamente, conforme sugerido por Galvani e Luchiari (2012). Os autores supracitados esclarecem que nessa proposta de intervalos percentis, 5\% da amostra corresponde aos anos muito secos, $20 \%$ aos secos, $50 \%$ aos habituais, $20 \%$ aos chuvosos e $5 \%$ aos muito chuvosos. Dessa forma, a quantidade de anos 
com regime habitual (50\%) condiz com a proporção lógica esperada para a quantidade de anos com regime excepcional - chuvoso $(25 \%)$ e seco $(25 \%)$.

\section{Resultados e Discussões}

\subsection{A distribuição das chuvas ao longo do ano civil no estado de Goiás e Distrito Federal}

Conforme exposto por Nimer (1979) e Nascimento (2016), o clima do estado de Goiás e do Distrito Federal é marcado pela ocorrência de dois períodos bem distintos: primavera/verão quente e chuvoso e outono/inverno com temperaturas mais amenas e estiagem. Segundo esses autores, o período chuvoso é compreendido pelo mês de outubro de um ano até abril do ano seguinte. A título de exemplo, a Figura 2, que indica as normais climatológicas de 1961 a 1990 do Instituto Nacional de Meteorologia (INMET) referente à Goiânia, capital do estado de Goiás, mostra queo ano civil retrata o final do período chuvoso de um ano anterior (janeiro a abril) e o começo do período chuvoso seguinte (outubro a dezembro). Dessa forma, o ano-padrão delimitado com base no ano civil é capaz de representar o final do período chuvoso do ano anterior e o começo do período chuvoso, que se estende ao ano seguinte.

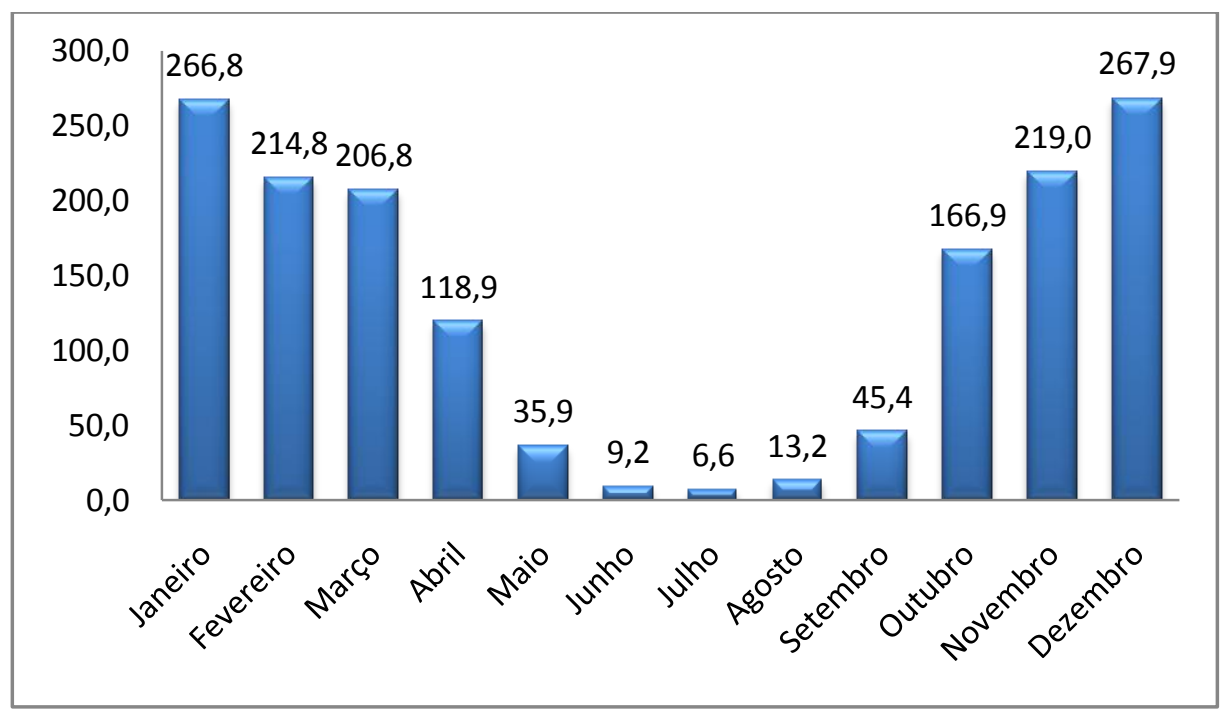

Figura 2 - Média da precipitação mensal para Goiânia-GO.

Elaboração: próprios autores, conforme Normais Climatológicas do INMET (1961/1990)

Caso diferente é capaz de ocorrer em outras regiões do Brasil, como é o caso das cidades de João Pessoa (PB) e Porto Alegre (RS), nas quais o período chuvoso condiz com o ano civil. Em João Pessoa (Figura 3A), o período de chuvas compreende os meses de janeiro a setembro, ao passo que em Porto Alegre (Figura 3-B) a chuva encontra-se bem distribuída ao longo de todos os meses do ano. 


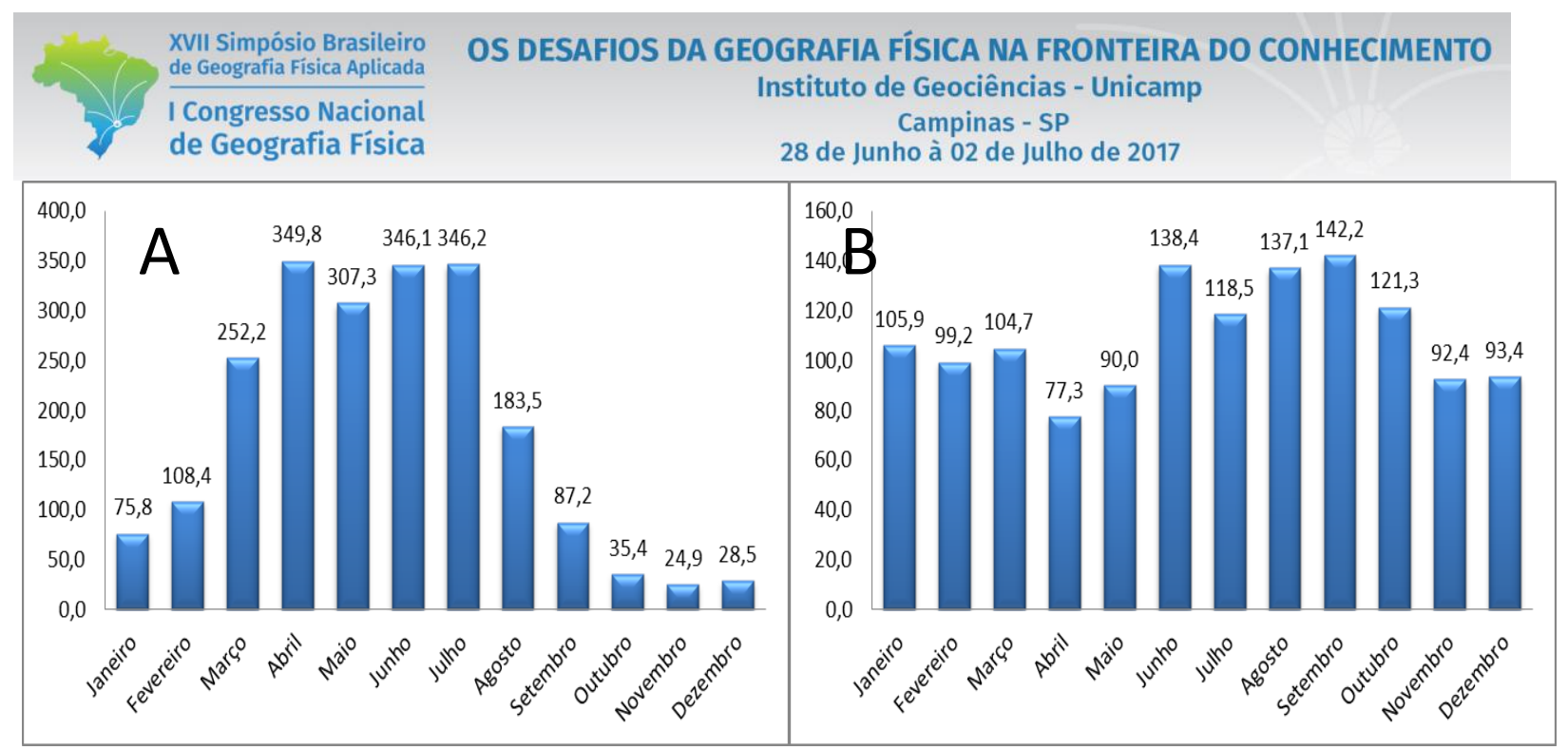

Figura 3 - Média de precipitação para João Pessoa - PB (A) e Porto Alegre - RS (B) Elaboração: próprios autores, conforme Normais Climatológicas do INMET (1961/1990)

As diferentes condições de distribuição das chuvas ao longo do ano podem ser explicadas pelo efeito da maritimidade/continentalidade, pela latitude e, principalmente, devido aos sistemas atmosféricos atuantes e gerados de chuvas nas diferentes localidades do Brasil.

No caso de Goiás e Distrito Federal, conforme apontado por Nascimento (2017), os principais sistemas atmosféricos produtores de chuva são a $\mathrm{mEc}$ e a ZCAS, que possuem maior atuação nos meses representativos da primavera (outubro a dezembro) e verão (janeiro a março), conforme exposto na passagem:

Durante o solstício de verão no Hemisfério Sul, o maior ângulo de incidência da radiação solar ocasiona num maior aquecimento da superfície terrestre com relação à oceânica. Devido a esse aquecimento desigual, a zona de baixa pressão localizada na região amazônica se expande e domina por grande parte do território brasileiro, intensificando a atuação da mEc sobre o país, repercutindo seu domínio sobre o estado de Goiás e Distrito Federal - o que condiciona o período chuvoso. As chuvas que ocorrem durante o verão são intensificadas pela atuação da ZCAS que, ao encontro do calor, umidade e convecção proveniente da região Amazônica com as frentes polares, repercutem nas chuvas frontais (NASCIMENTO, 2017, p. 36).

Na sequência é apresentada a definição dos anos-padrão segundo as duas possibilidades: pelo ano civil e a partir do ano hidrológico, sendo retratada a diferença entre o regime das chuvas (habitual/seco/chuvoso) definido para cada ano da série temporal - segundo tais metodologias.

\subsection{A definição dos anos-padrão a partir do ano civil e do hidrológico}

A Figura 4 representa a definição dos anos-padrão do estado de Goiás e do Distrito Federal a partir do ano civil, com a indicação dos anos definidos como muito seco (marrom), seco (laranja), habitual (amarelo 
XVII Simpósio Brasileiro de Geografia Fisica Aplicada

I Congresso Nacional de Geografia Física
OS DESAFIOS DA GEOGRAFIA FÍSICA NA FRONTEIRA DO CONHECIMENTO

Instituto de Geociências - Unicamp

Campinas - SP

28 de Junho à 02 de Julho de 2017

claro), chuvoso (azul claro) e muito chuvoso (azul escuro), havendo a ocorrência de 11 anos definidos como ano-padrão habitual (55\%), 5 como ano-padrão seco (25\%) e 4 como ano-padrão chuvoso (20\%).

\begin{tabular}{|c|c|c|c|c|c|c|c|c|c|c|c|c|c|}
\hline Ano/Estação & Posse-GO & Formosa-GO & Pirenópolis-GO & Goiás-GO & Aragarças-GO & Goiânia-GO & Ipameri-GO & Rio Verde-GO & Jataí-GO & Catalão-GO & Brasília-DF & Peixe-TO & Capinópolis-MG \\
\hline 1997 & 1427,80 & 1257,20 & 1635,20 & 1815,30 & & 1596,10 & 1443,40 & 1488,30 & 1873,80 & 1510,70 & 1512,00 & \begin{tabular}{l|l|}
0 & 1803,70
\end{tabular} & 1633,00 \\
\hline 1998 & 1351,40 & 1261,50 & 1604,10 & 1488,70 & 1278,80 & 1574,40 & 1518,90 & 1391,00 & 1444,70 & 1205,30 & 1375,20 & \begin{tabular}{l|l|}
0 & 1139,30 \\
\end{tabular} & 1238,90 \\
\hline 1999 & 1482,60 & 1374,90 & 1491,90 & 1777,40 & 1180,20 & 1347,50 & 1271,90 & 1172,40 & 1257,10 & 1364,00 & 1236,70 & \begin{tabular}{l|l|}
0 & 1530,80 \\
\end{tabular} & 1177,40 \\
\hline 2000 & 1636,00 & 1425,20 & 1738,50 & 1869,00 & 1336,80 & 1833,50 & 1642,50 & 2229 & 1718,00 & 1561,70 & 1377,30 & & 1568,00 \\
\hline 2001 & 1349,80 & 1248,60 & 1490,80 & 1773,30 & 1371,40 & 1766,90 & 1411,10 & 1441,80 & 1780,30 & 1396,80 & 1285,50 & \begin{tabular}{l|l|}
0 & 1133,00 \\
\end{tabular} & 1189,90 \\
\hline 2002 & 1221,20 & 995,50 & 1350,90 & 1209,80 & 1483,40 & 1536,40 & 1102,20 & 1313,30 & 1673,00 & 1281,50 & 1389,50 & \begin{tabular}{l|l|}
0 & 1528,00 \\
\end{tabular} & 1224,70 \\
\hline 2003 & 1237,10 & 1223,90 & 1507,30 & 1620,20 & 1358,30 & 1541,00 & 1585,00 & 1562,30 & 1520,50 & 1365,10 & 1287,20 & \begin{tabular}{l|l|}
0 & 1263,50 \\
\end{tabular} & 1425,00 \\
\hline 2004 & 1330,60 & & 1964,20 & 1614,70 & 1586,00 & 1555,90 & 1789,10 & 1895,40 & 1626,00 & 1480,10 & 1619,00 & \begin{tabular}{l|l|}
0 & 1593,40
\end{tabular} & 1527,00 \\
\hline 2005 & 1613,20 & 1577,40 & 2095, & 2000,10 & 1390,60 & 1901 & 18 & 1534,10 & 1591,10 & 1456,80 & 1760,10 & \begin{tabular}{|l|l|}
0 & 1404,90 \\
\end{tabular} & 1608,70 \\
\hline 2006 & 1829 & 1544,00 & 1857,00 & 1740,70 & 1448,80 & 1705,10 & 1886,10 & 1673,00 & 1626,80 & 1444,30 & 1747,40 & \begin{tabular}{|l|l|}
0 & 1442,10 \\
\end{tabular} & 1567,30 \\
\hline 2007 & 820,80 & 1157,50 & 1843,20 & 1351,60 & 1372,20 & 1095,20 & 1311,10 & 1474,40 & 1474,40 & 1399,80 & 1167,00 & \begin{tabular}{|l|l|}
0 & 1168,10 \\
\end{tabular} & 1229,30 \\
\hline 2008 & 1423,30 & 1315,30 & 1792,50 & 1929,60 & 1628,40 & 1809,30 & 1499,20 & 1769,90 & 1879,2 & 1632,60 & 1589,10 & \begin{tabular}{l|l|}
0 & 1568,80 \\
\end{tabular} & 1627,70 \\
\hline 2009 & 1679,30 & 1633,50 & 2085,20 & 2338,5 & 1675,60 & 1767,90 & 1609,60 & 1743,80 & 1732,70 & 1573,80 & 1792,90 & \begin{tabular}{|l|l|}
0 & 1289,00 \\
\end{tabular} & 1762 \\
\hline 2010 & 1253,40 & 1176,30 & 1843,00 & 1216,20 & 1254,80 & 1555,90 & 1096,30 & 1488,00 & 1565,90 & 1349,30 & 1431,60 & \begin{tabular}{l|l|}
0 & 1355,40 \\
\end{tabular} & 1219,40 \\
\hline 2011 & 1497,20 & 1400,00 & 1641,00 & 1941,60 & 1746,20 & 1812,60 & 1529,10 & 1658,30 & 1514,40 & & 1558,80 & \begin{tabular}{|l|l|}
0 & 1321,00 \\
\end{tabular} & 1511,20 \\
\hline 2012 & 1060,40 & 1010,80 & 1512,30 & 1528,90 & 1312,60 & 1894,10 & 1336,60 & 1517,20 & 1792,20 & 1236,90 & 1480,10 & 976,80 & 1263,10 \\
\hline 2013 & 1461,50 & 1621,90 & 1966,30 & 1481,30 & 1612,90 & 1782,10 & 1526,90 & 1501,70 & 1536,80 & 1455,90 & 180 & 1657,80 & 1486,80 \\
\hline 2014 & 1298,50 & 1224,60 & 1711,80 & 1379,20 & 1295,60 & 1662,00 & 1146,00 & 1536,10 & 1703,60 & 1225,00 & 1680,40 & \begin{tabular}{|l|l|}
0 & 1466,80 \\
\end{tabular} & 1054,40 \\
\hline 2015 & 1095,50 & 1036,50 & 1475,20 & 1321,00 & 1417,30 & 1503,40 & 1335,00 & 1612,30 & 1454,30 & 1315,70 & 1252,70 & \begin{tabular}{l|l|}
0 & 1041,60
\end{tabular} & 1530,40 \\
\hline 2016 & 794,60 & 1210,30 & 1465,00 & 1417,50 & 1286,80 & 1362,00 & 1409,80 & 1415,50 & 1601,90 & 1293,40 & 1192,90 & \begin{tabular}{l|l|}
0 & 1077,70 \\
\end{tabular} & 1363,60 \\
\hline te & & & $\mathrm{Se}$ & ec & co & & & & & ang & & & aves \\
\hline
\end{tabular}

Figura 4 - Classificação dos anos-padrão de Goiás e Distrito Federal a partir do ano civil.

Elaboração: próprios autores.

A série temporal inicia com o regime habitual prevalecendo em 1997 e 1998, havendo, na sequencia, o regime seco em 1999 e o chuvoso em 2000. O ano de 1999 se destaca por ser aquele com maior ocorrência de estações pertencentes ao regime seco.

Entre os anos de 2001 e 2006 predomina a condição de regime habitual na área em estudo, a exceção é para os anos de 2002 e 2005, nos quais prevalece o regime seco e chuvoso, respectivamente. Nesse intervalo, vale destacar o ano de 2003, em que todas as estações apresentam o regime habitual para a área em estudo.

De 2007 a 2009 prevalece o regime excepcional das precipitações, com o ano de 2007 definido como anopadrão seco e os dois anos seguintes (2008 e 2009) como ano-padrão chuvoso. O ano de 2009 também se destaca entre a série temporal por ser aquele com maior proporção das estações classificadas como regime chuvoso.

No intervalo compreendido entre os anos de 2010 e 2014, o predomínio é do regime habitual, com a ocorrência do regime seco nos dois últimos anos da série temporal analisada: 2015 e 2016.

A definição dos anos-padrão a partir do ano hidrológico é representada pela Figura 5, pela qual é possível perceber que 12 anos foram definidos como ano-padrão habitual (60\%), 3 como ano-padrão chuvoso (15\%) e apenas 2 como ano-padrão seco (10\%). Vale destacar que 3 anos não puderam ser classificados por apresentarem a mesma proporção de ocorrência de dois regimes de chuvas, como se deu em 2001/2002 (habitual/chuvoso), 2004/2005 (habitual/ seco) e 2013/2014 (chuvoso/seco). 


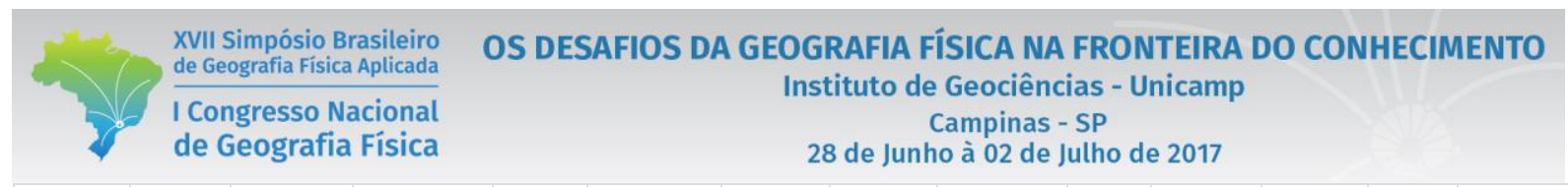

Ano/Estação Posse-GO Formosa-GO Pirenópolis-GO Goiás-GO Aragarças-GO Goiânia-GO Ipameri-GO Rio Verde-GO Jataí-GO Catalão-GO Brasilia-DF Peixe-TO Campinópolis-MG

\begin{tabular}{|c|c|c|c|c|c|c|c|c|c|c|c|c|c|}
\hline & & & & & & & & & tatar & alão-c & asilia-DF & TO & Campinópolis-MG \\
\hline $1996 / 1997$ & 1832,20 & 1503,30 & 1832,20 & & 1311 & 1928,80 & 1565,90 & 870,80 & 1132,60 & 1646,40 & 1648,70 & 1876,60 & 1433,40 \\
\hline $1997 / 1998$ & 1378,30 & 1232,30 & 1378,30 & 1347,70 & 1586,60 & 1388,30 & 1530,80 & 1358,90 & 1611,90 & 1307,60 & 1286,00 & 1283,30 & 1502,50 \\
\hline $1998 / 1999$ & 1377,90 & 1127,70 & 1377,90 & 1619,60 & 1144,00 & 1252,70 & 1252,20 & 1326,50 & 1235,20 & 1352,70 & 1105,10 & 1181,00 & 1291,10 \\
\hline $1999 / 2000$ & 1726,00 & 1588,80 & 1726,00 & 1797,00 & 1232,20 & 1709,20 & 1432,40 & 1629,20 & 1615,10 & 1453,40 & 1382,80 & 1960,70 & 942,50 \\
\hline 2000/2001 & 1634,80 & 1126,70 & 1634,80 & 1620,30 & 1215,60 & 1730,20 & 1300,80 & 1892,30 & 1573,60 & 1334,60 & 1409,00 & 1453,80 & 1416,50 \\
\hline 2001/2002 & 1532,40 & 1233,40 & 1532,40 & 1803,70 & 1773,10 & 1894,80 & 1543,00 & 1405,90 & 59,40 & 1528,60 & 1310,50 & 1372,90 & 1365,10 \\
\hline $2002 / 2003$ & 1682,50 & 1263,20 & 1682,50 & 1603,20 & 1471,80 & 1437,70 & 1432,90 & 1534,20 & 1447,90 & 1275,60 & 1386,90 & 1740,60 & 1402,10 \\
\hline $2003 / 2004$ & 1660,70 & & 1660,70 & 1472,00 & 1562,90 & 1644,20 & 1758,10 & 1880,50 & 1501,60 & 1556,80 & & 1298,30 & 1389,60 \\
\hline $2004 / 2005$ & 1874,80 & 1203,70 & 1874,80 & 1784,70 & 1219,60 & 1587,00 & 1486,00 & 1113,00 & 1517,10 & 1224,50 & 1361,60 & 1488,80 & 1518,80 \\
\hline $2005 / 2006$ & 1852,30 & 1353,00 & 1852,30 & 1709,90 & 1323,20 & 1780,50 & 1895,20 & 1755,40 & 1589,20 & 1545,50 & 1551,30 & 1267,60 & 1419,00 \\
\hline 2006/2007 & & 1647,40 & 50 & 1867,10 & 1672,60 & 1433,10 & 9.20 & 1951,40 & 1682,10 & 1526,30 & 1626,10 & 1332,00 & 1616,60 \\
\hline $2007 / 2008$ & 1603,40 & 1140,70 & 1603,40 & 1185,50 & 1522,90 & 1670,90 & 1419,00 & 1710,30 & 1931,70 & 1516,50 & 1411,60 & 1424,10 & 1521,10 \\
\hline $2008 / 2009$ & 1837,70 & 1399,60 & 1837,70 & 1990,90 & 1434,50 & 1447,80 & 1439,10 & 1340,30 & 1246,70 & 1437,70 & 1582,90 & 1399,00 & 1406,50 \\
\hline $2009 / 2010$ & 1882,70 & 1414,70 & 1882,70 & 1727,20 & 1636,30 & 1624,40 & 1155,10 & 1749,70 & 1990,20 & 1435,20 & 1594,90 & 1183,70 & 1644,00 \\
\hline $2010 / 2011$ & 1864,30 & 1298,90 & 1864,30 & 1759,30 & 1597,00 & 1829,40 & 1415,60 & 1728,40 & 1620,80 & 1679,80 & 1392,00 & 1408,70 & 1574,30 \\
\hline $2011 / 2012$ & 1634,50 & 1281,40 & 1634,50 & 1905,30 & 1302,70 & 2167,60 & 1620,20 & 1562,70 & 1719,30 & 1390,30 & 1679,00 & 1164,60 & 1242,60 \\
\hline 2012/2013 & 1788,30 & 1375,60 & 1788,30 & 1222,00 & 1552,50 & 1375,40 & 1321,70 & 1481,40 & 1659,20 & 1272,40 & 1726,30 & 1194,30 & 1379,50 \\
\hline $2013 / 2014$ & 1874,00 & 1402,50 & 1874,00 & \begin{tabular}{|l|}
1508,90 \\
\end{tabular} & 1427,30 & 2010,30 & 1173,50 & 1197,50 & \begin{tabular}{|l|}
1291,20 \\
\end{tabular} & 1212,90 & 1701,40 & 1627,90 & 1080,60 \\
\hline $2014 / 2015$ & 1474,30 & 1208,70 & 1474,30 & 1583,10 & 1420,70 & 1510,60 & 1491,80 & 1911,80 & 1711,00 & 1397,00 & 1605,80 & 1432,50 & 1521,10 \\
\hline 2015/2016 & 1394,60 & 934,70 & 1394,60 & 1096,90 & 1215,40 & 1448,00 & 1334,30 & 1462,30 & 1500,60 & 1445,40 & 1079,10 & 924,80 & 1283,90 \\
\hline
\end{tabular}

Regime: $\quad$ Muito Seco $\square$ Seco $\quad$ Habitual $\square$ Chuvoso

Figura 5 - Classificação dos anos-padrãode Goiás e Distrito Federal conforme a partirdo ano hidrológico.

Elaboração: próprios autores.

O primeiro ano hidrológico da série temporal, 1996/1997, apresentou o predomínio de regime chuvoso. Nos anos seguintes, 1997/1998 e 1998/1999, houve o predomínio do regime seco e chuvoso, respectivamente.

Entre 1999/2000 e 2014/2015, praticamente todos os anos foram definidos como regime habitual, com exceção dos anos de 2006/2007 e 2009/2010, em que prevaleceu a condição de regime chuvoso entre as estações meteorológicas. O último ano hidrológico da série temporal analisada, 2015/2016, foi definido como seco.

Conforme indicado pela Figura 6, houve correspondência da classificação dos anos-padrão a partir do calendário civil e hidrológico em metade da série temporal. A condição de regime habitual se repetiu em 8 anos (40\%), conforme pode ser visto entre os anos de: 1997/1998 e 1998; 2000/2001 e 2001; 2002/2003 e 2003; 2003/2004 e 2004; 2005/2006 e 2006; 2010/2011 e 2011; 2011/2012 e 2012; e 2012/2013 e 2013. Ao passo que a condição do regime seco coincidiu entre os anos de 1998/1999 e 1999 e 2015/2016 e 2016.

Grande destaque deve ser dado ao ano hidrológico de 2006/2007, que foi classificado como chuvoso, diferente da metodologia baseada no ano civil, segundo a qual ele foi definido como seco - regimes totalmente distintos. Essa condição adversa entre as duas metodologias continua nos próximos anos hidrológicos (2007/2008 e 2008/2009), classificados como habituais, ao passo que pela metodologia dos anos civis os anos de 2008 e 2009 foram definidos como chuvosos.

Já o ano hidrológico de 2009/2010 foi classificado como chuvoso, diferente do ano civil de 2010 - ao qual o regime de chuvas foi definido como habitual. Isso indica que o regime chuvoso do ano hidrológico 


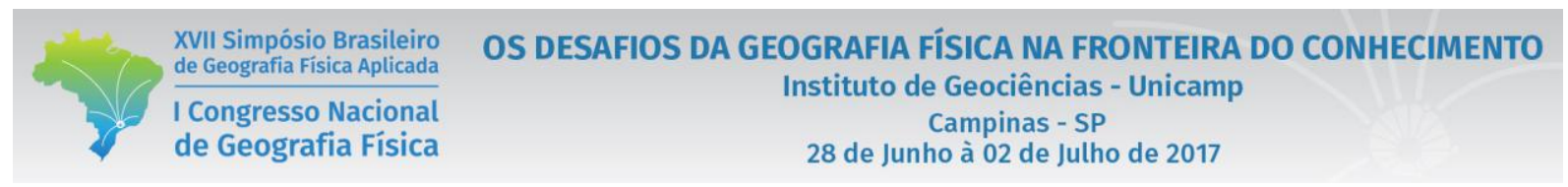

2009/2010 se deu em virtude dos maiores acumulados de precipitação que foi indicado para o mês de dezembro de 2009 por Nascimento (2016) e que, possivelmente, teve continuidade nos meses seguintes de 2010.

\begin{tabular}{|c|c|c|c|}
\hline Ano Civil & $\%$ & Ano Hidrológico & $\%$ \\
\hline 1997 & 62 & $1996 / 1997$ & 62 \\
\hline 1998 & 62 & $1997 / 1998$ & 54 \\
\hline 1999 & 62 & 1998/1999 & 85 \\
\hline 2000 & 62 & $1999 / 2000$ & 69 \\
\hline 2001 & 54 & $2000 / 2001$ & 69 \\
\hline 2002 & 69 & $2001 / 2002$ & 38 (habitual e chuvoso \\
\hline 2003 & 100 & $2002 / 2003$ & 69 \\
\hline 2004 & 62 & $2003 / 2004$ & 38 \\
\hline 2005 & 62 & $2004 / 2005$ & 38 (habitual e seco) \\
\hline 2006 & 54 & $2005 / 2006$ & 77 \\
\hline 2007 & 54 & $2006 / 2007$ & 62 \\
\hline 2008 & 62 & $2007 / 2008$ & 69 \\
\hline 2009 & 85 & $2008 / 2009$ & 77 \\
\hline 2010 & 62 & $2009 / 2010$ & 46 \\
\hline 2011 & 54 & 2010/2011 & 5 \\
\hline 2012 & 54 & $2011 / 2012$ & 46 \\
\hline 2013 & 62 & $2012 / 2013$ & 54 \\
\hline 2014 & 54 & $2013 / 2014$ & 38 (seco e chuvoso) \\
\hline 2015 & 62 & $2014 / 2015$ & 62 \\
\hline 2016 & 62 & $2015 / 2016$ & 62 \\
\hline
\end{tabular}

Figura 6 - Correspondência da definição dos anos-padrão a partir do ano civil e hidrológico Elaboração: próprios autores.

Os anos hidrológicos de 2010/2011 a 2014/2015 foram definidos como habituais, tendo quase correspondência a definição do regime realizada a partir do ano civil - a única exceção foi o ano de 2015, classificado como seco.

\section{Considerações Finais}

A definição dos anos-padrão do regime habitual e excepcional das chuvas comumente tem sido realizada a partir do ano civil. Contudo, considerando a diversidade climática do território brasileiro e a existência de distintos regimes de precipitação nas diferentes localidades do país, possivelmente o calendário civil não seja o mais adequado.

Conforme apontado no trabalho, enquanto em algumas localidades o período chuvoso se encaixa perfeitamente ao longo dos meses de um ano civil, em outras regiões, como é o caso do estado de Goiás e do Distrito Federal, o período chuvoso compreende os últimos meses de um ano e os primeiros do ano seguinte. 


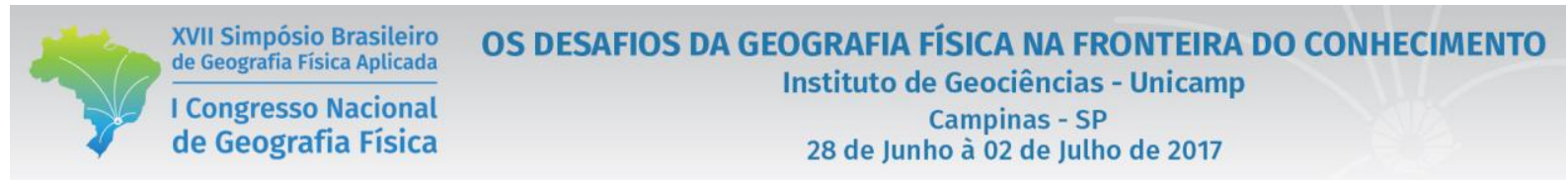

Como continuidade dessa pesquisa, ainda preliminar, sugere-se o desenvolvimento de estudos que busquem comparar o regime e o ritmo das chuvas entre os anos-padrão habitual e excepcional (seco e chuvoso) definidos a partir do ano civil e hidrológico, e, assim, constatar a não adequação do calendário civil para a definiçao dos anos-padrão, essencialmente por não compreender toda a extensão do período chuvoso de algumas localidades do país e, principalmente, não retratar a ocorrência dos sistemas atmosféricos responsáveis pela condição habitual ou excepcional ao longo de todo período de chuvas.

\section{Referências}

AOUAD, M. S. Tentativa de classificação climática para o Estado da Bahia: uma análise quantitativa dos atributos locais, associada à análise qualitativa do processo genético. Rio de Janeiro: IBGE, 1982. 80p.

BARROS, Juliana Ramalho. A chuva no Distrito Federal: o regime e as excepcionalidades do ritmo. 2003. $221 \mathrm{f}$. Dissertação (Mestrado)- Instituto de Geociências e Ciências Exatas, Universidade Estadual Paulista, Rio Claro, 2003.

.; ZAVATTINI, J. A. Bases conceituais em climatologia geográfica.Mercator, v. 08, n. 16, p. 255-261, 2009.

BOIN, Marcos Norberto. Chuvas e erosões no oeste paulista: uma análise climatológica aplicada. 2000. 264 f. Tese (doutorado) - Universidade Estadual Paulista, Instituto de Geociências e Ciências Exatas, 2000

CAMPOS, A. B. de. et al. Análise do comportamento espacial e temporal das temperaturas e pluviosidades no Estado de Goiás. In: ALMEIDA, M. G. de (Org.). Abordagens geográficas de Goiás: o natural e o social na contemporaneidade. Goiânia: IESA, 2002. p. 91-118.

DEUS, R. M. M. ; NASCIMENTO, D. T. F. . Como a mídia tem noticiado os eventos climáticos extremos no estado Goiás. In: ENCONTRO NACIONAL DE GEÓGRAFOS, 2016, São Luís. Anais do ENG, 2016. p. 1-10.

MONTEIRO, C. A. F. A dinâmica climática e as chuvas do estado de São Paulo: estudo geográfico sob forma de atlas. São Paulo: IGEOG, 1973.

A análise rítmica em climatologia: problemas da atualidade climática em São Paulo e achegas para um programa de trabalho. São Paulo: Universidade de São Paulo, 1971. (Série Climatologia, 1).

NASCIMENTO, D. T. F. Chuvas no estado de Goiás e no Distrito Federal a partir de estimativas por satélite e circulação atmosférica. Tese (Doutorado em Geografia) - Instituto de Estudos Socioambientais, Universidade Federal de Goiás, Goiâna, 2016.

NIMER, E. Climatologia do Brasil. Rio de Janeiro: IBGE, 1979. 422p.

PINKAYAN, S. ConditionalprobabilitiesofocurrenceofWetandDryYears Over a Large Continental Area. Colorado: StateUniversity, Boulder-Co, 1966. 54 p.

STRAHLER, A. N. PhysicalGeography. Nova York: John Wiley, 1951.

XAVIER, T. DE M. B. S.; SILVA, J. F.; REBELlO, E. R.A Técnica dos Quantis e suas aplicações em Meteorologia, Climatologia, Hidrologia, com ênfase para as regiões brasileiras. Brasília: Ed. Thesaurus, 2002. $140 \mathrm{p}$.

ZAVATtini, J. A. A Dinâmica Atmosférica e a distribuição das chuvas no Mato Grosso do Sul. 1990. Tese (Doutorado em Geografia Física)-Faculdade de Filosofia, Letras e Ciências Humanas, Universidade de São Paulo, São Paulo, 1990. 